\title{
Parietal white matter lesions in Alzheimer's disease are associated with cortical neurodegenerative pathology, but not with small vessel disease
}

\author{
Kirsty E. McAleese ${ }^{1} \cdot$ Lauren Walker $^{1} \cdot$ Sophie Graham $^{1} \cdot$ Elisa L. J. Moya $^{2} \cdot$ Mary Johnson $^{1} \cdot$ Daniel Erskine $^{1}$ \\ Sean J. Colloby ${ }^{1} \cdot$ Madhurima Dey $^{3} \cdot$ Carmen Martin-Ruiz $^{1} \cdot$ John-Paul Taylor $^{1} \cdot$ Alan J. Thomas ${ }^{1}$. \\ Ian G. McKeith ${ }^{1}$ Charles De Carli ${ }^{4} \cdot$ Johannes Attems $^{1}$
}

Received: 20 April 2017 / Revised: 6 June 2017 / Accepted: 6 June 2017 / Published online: 21 June 2017

(C) The Author(s) 2017. This article is an open access publication

\begin{abstract}
Cerebral white matter lesions (WML) encompass axonal loss and demyelination, and the pathogenesis is assumed to be small vessel disease (SVD)-related ischemia. However, WML may also result from the activation of Wallerian degeneration as a consequence of cortical Alzheimer's disease $(\mathrm{AD})$ pathology, i.e. hyperphosphorylated tau $(\mathrm{HP} \tau)$ and amyloid-beta $(\mathrm{A} \beta)$ deposition. WML seen in $\mathrm{AD}$ have a posterior predominance compared to non-demented individuals but it is unclear whether the pathological and molecular signatures of WML differ between these two groups. We investigated differences in the composition and aetiology of parietal WML from $\mathrm{AD}$ and non-demented controls. Parietal WML tissue from 55 human post-mortem brains (AD, $n=27$; non-demented controls, $n=28$ ) were quantitatively assessed for axonal loss and demyelination, as well as for cortical HP $\tau$ and $\mathrm{A} \beta$ burden and SVD. Biochemical assessment included Wallerian degeneration protease calpain and the myelin-associated glycoprotein (MAG) to proteolipid protein (PLP) ratio (MAG:PLP) as
\end{abstract}

Electronic supplementary material The online version of this article (doi:10.1007/s00401-017-1738-2) contains supplementary material, which is available to authorized users.

Kirsty E. McAleese

Kirsty.mcaleese@ncl.ac.uk

$\triangle$ Johannes Attems

Johannes.Attems@newcastle.ac.uk

1 Institute of Neuroscience, Campus for Ageing and Vitality, Newcastle University, Newcastle upon Tyne NE4 5PL, UK

2 Department of Biology, University of Granada, Granada, Spain

3 School of Biology, University of St Andrews, Fife, UK

4 Department of Neurology, University of California, Davis, CA, USA a measure of hypoperfusion. WML severity was associated with both axonal loss and demyelination in AD, but only with demyelination in controls. Calpain was significantly increased in WML tissue in AD, whereas MAG:PLP was significantly reduced in controls. Calpain levels were associated with increasing amounts of cortical AD-pathology but not SVD. We conclude that parietal WML seen in AD differ in their pathological composition and aetiology compared to WML seen in aged controls: WML seen in $\mathrm{AD}$ may be associated with Wallerian degeneration that is triggered by cortical AD-pathology, whereas WML in aged controls are due to ischaemia. Hence, parietal WML as seen on MRI should not invariably be interpreted as a surrogate biomarker for SVD as they may be indicative of cortical AD-pathology, and therefore, AD should also be considered as the main underlying cause for cognitive impairment in cases with parietal WML.

Keywords White matter lesion - White matter hyperintensity - Alzheimer's disease - Small vessel disease . Hyperphosphorylated tau $\cdot$ Wallerian degeneration

\section{Introduction}

Cerebral white matter lesions (WML) are a frequent finding at post-mortem histological examination of brains from both demented and non-demented elderly. They primarily encompass loss of integrity of the cerebral white matter due to rarefaction, which morphologically appear as demyelination when visualized with histochemical myelin stains and may be due to loss of the axonal myelin sheath or axonal loss [25]. WML appear as white matter hyperintensities (WMH) on pre- and post-mortem T2-weighted magnetic resonance imaging (MRI) [27], and as altered diffusivity on 
diffusion tensor imaging (DTI) [7]. The burden of WMH increases with age [50] and is associated with cognitive decline and risk of dementia [14]. In Alzheimer's disease (AD) patients WMH are found in up to $89 \%$ of cases [5] and are more severe than WMH seen in the non-demented elderly [40, 67].

WML/WMH are usually assumed to represent ischemiaassociated demyelination and axonal loss due to arteriopathy of the white matter arteries and arterioles, i.e. small vessel disease (SVD) [47]. Therefore, the detection of in vivo WMH often supports the diagnosis of cerebrovascular disease and, in patients with cognitive impairment, the diagnosis of vascular cognitive impairment/dementia (VCI/ $\mathrm{VaD}$ ) over other forms of dementia such as AD [41]. However, previous neuroimaging $[34,51]$ and neuropathological studies [40] suggest a multifactorial aetiology of WMH, in addition to SVD it may also include degenerative axonal loss secondary to the deposition of cortical AD pathology, i.e. hyperphosphorylated tau (HP $\tau)$ and amyloid-beta $(\mathrm{A} \beta)$. Here, axonal loss in white matter could either occur as a consequence of cortical neuronal loss (later stages of $\mathrm{AD}$ ), or as a result of retrograde Wallerian degeneration, i.e. rapid irreversible fragmentation and destruction of the distal axon [38]. One of the main triggers of Wallerian degeneration in $\mathrm{AD}$ is the disruption and/or blockage of anterograde fast axonal transport [55]. Eventually impaired axonal transport leads to axonal dysregulation and increased intracellular calcium concentration activating the calcium-dependent cysteine protease calpain that mediates cytoskeletal breakdown, demyelination and axonal fragmentation [12, 13, 39].

In-vivo DTI studies support the concept of AD-associated axonal changes as they have demonstrated specific topographical white matter changes, i.e. reduced axonal integrity, axonal swelling and demyelination that occur exclusively in AD patients. These changes include reduced integrity in white matter tracts connected to the medial temporal lobe (MTL) [2,31], the cingulum and in the tracts of the temporo-parietal regions such as the superior longitudinal fasciculus $[1,7]$. These changes in white matter structure have been directly associated with Wallerian degeneration independent of cortical atrophy [3, 7, 28]. Moreover, $\mathrm{AD}$ cases with severe cortical AD pathology and severe WML exhibited only minimal SVD pathology at post-mortem examination $[17,40]$, indicating that SVD was not the primary cause of WML in these cases.

In addition, cerebral amyloid angiopathy (CAA), a subtype of SVD characterized by the accumulation of $A \beta$ in leptomeningeal, cortical and capillary vessel walls is seen in $80-100 \%$ of AD cases [4] was suggested to cause ischemia of the white matter as the presence of CAA has been shown to be associated with increased demyelination [59] and AD patients with CAA had higher burdens of
WMH compared to AD patients without CAA [26]. However, others found no relationship between WMH and CAA [56] and the relationship between CAA and the pathogenesis of WML has not yet been clarified.

The underlying aetiology of WML is not restricted to SVD and may indeed be indicative of AD pathology. However, it is not clear whether WML associated with cortical AD pathology differ in their pathological and molecular signatures from WML that are associated with SVD and such data are needed to further our understanding of the pathogenesis of WML. This is crucial as the current clinical criteria for $\mathrm{VaD} / \mathrm{VCI}[22]$ and mixed $\mathrm{AD} / \mathrm{VaD}$ [16] are based on the detection of WMH, which are invariably interpreted as a surrogate marker of SVD resulting in misdiagnosis with a detrimental impact on the choice of therapeutic interventions. Therefore, we investigated post-mortem brain tissue of $\mathrm{AD}$ and aged controls to identify differences in the composition and aetiology of WML in the parietal lobe using pathological and biochemical methods.

\section{Methods}

\section{Study cohort}

Our study cohort consisted of 55 human post-mortem brains (mean age $84.02 \pm 7.94$ years; male: 24 , female: 31). During life, all dementia subjects underwent clinical assessments by board certified Old Age Psychiatrists or Neurologists and most were assessed in prospective research studies with repeated cognitive evaluation including the Mental State Examination (MMSE) [19] (MMSE scores were available for 18 out of 27 AD cases and for 6 out of 28 controls). All cases had a clinical review of records after death (AJT) at Newcastle Brain Tissue Resource (NBTR) and control subjects showed no evidence of cognitive impairment and had normal everyday functioning up until death. AD cases were confirmed as having a clinical dementia due to AD. Brain tissue was obtained at autopsy and stored within the NBTR in accordance with Newcastle University Ethics Board (The Joint Ethics Committee of Newcastle and North Tyneside Health Authority, reference: 08/H0906/136). After autopsy the left hemisphere, brainstem and cerebellum were dissected in coronal planes approximately $0.7 \mathrm{~cm}$ intervals and snap frozen between copper plates at $-120{ }^{\circ} \mathrm{C}$ and stored at $-80{ }^{\circ} \mathrm{C}$. The right hemisphere, brainstem and cerebellum were immersion fixed in $10 \%$ buffered aqueous formaldehyde solution for 6 weeks and then subsequently dissected in coronal planes approximately $0.7 \mathrm{~cm}$ intervals and paraffin-embedded. All brains underwent neuropathological assessment according to the National Institute on Aging-Alzheimer's Association 
(NIA-AA) criteria [44] that included assessment of Thal phases of $A \beta$ deposition [57], Braak staging of neurofibrillary pathology [10] and Consortium to Establish a Registry for Alzheimer's Disease (CERAD) scoring [43]. Additional neuropathological scoring of Lewy body pathology [9, 42], vascular pathology contribution to cognitive impairment (vascular impairment neuropathological guidelines (VCING)) [53], TDP-43 inclusions [30] and CAA [46] was performed. Cases did not contain any infarcts or cerebral haemorrhages. The final clinico-pathological diagnosis was AD in 27 cases, while no cognitive impairment and only mild age-associated neuropathological changes were seen in 28 cases (controls) (Table 1).

\section{Histological procedures}

Paraffin-embedded serial sections from parietal blocks (Brodmann area 40/22) were cut at $6 \mu \mathrm{m}$ thickness and mounted onto superfrost plus charged glass slides (Thermo Shandon, Cheshire, UK). The parietal lobe was selected as $\mathrm{AD}$ patients frequently show WMH in the posterior region inclusive of the parietal white matter [67] and this region contains large amounts of white matter for pathological assessment. Sections underwent histological staining with Bielschowsky silver stain (cold method) [37] for assessment of axonal density, myelin stain luxol fast blue (LFB) to assess WML area and myelin pallor (as a measure

Table 1 Demographic and neuropathological characteristics of study cohort

\begin{tabular}{|c|c|c|c|}
\hline & $\mathrm{AD}$ & Control & Statistic $_{(d f)}, p$ value \\
\hline Cohort number & 27 & 28 & \\
\hline Mean age, years $( \pm S D)$ & $84.01(6.84)$ & $84.04(9.00)$ & $t_{(53)}=0.17, p=0.987$ \\
\hline Gender M:F & $11: 16$ & $13: 15$ & $\chi_{(1)}^{2}=0.181, p=0.671$ \\
\hline Mean PMD, hours $( \pm \mathrm{SD})$ & $51.53(23.70)$ & $53.00(24.84)$ & $t_{(31)}=1.73, p=0.864$ \\
\hline Thal A $\beta$ phase [57] & $\begin{array}{l}\text { Phase } 4, n=2 \\
\text { Phase } 5, n=25\end{array}$ & $\begin{array}{l}\text { Phase } 0, n=8 \text { Phase } 1, n=9 \text { Phase } 2, n=5 \text { Phase } 3 \text {, } \\
\quad \begin{array}{l}n=3 \\
\text { Phase } 4, n=2 \\
\text { Phase } 5, n=1\end{array}\end{array}$ & $U_{(53)}=16.5, p=0.0001$ \\
\hline Braak NFT stage [10] & $\begin{array}{l}\text { NFT stage } 5, n=3 \\
\text { NFT stage } 6, n=24\end{array}$ & $\begin{array}{l}\text { NFT stage } 0, n=2 \text { NFT stage } 1, n=3 \text { NFT stage } 2, \\
n=11 \text { NFT stage } 3, n=11 \text { NFT stage } 4, n=1\end{array}$ & $U_{(53)}=0.500, p=0.0001$ \\
\hline CERAD [43] & $\mathrm{C}, n=27$ & Negative, $n=23 \mathrm{~A}, n=3 \mathrm{~B}, n=2$ & - \\
\hline NIA-AA [44] & High, $n=27$ & $\begin{array}{l}\text { No, } n=8 \\
\text { Low, } n=18 \text { Intermediate, } n=2\end{array}$ & - \\
\hline Braak LB stage [9] & $\begin{array}{l}\text { LFB stage } 0, n=25 \\
\text { LFB stage } 1, n=0 \\
\text { LFB stage } 2, n=1 \\
\text { LFB stage } 3, n=1\end{array}$ & $\begin{array}{l}\text { LFB stage } 0, n=24 \\
\text { LFB stage } 1, n=1 \\
\text { LFB stage } 2, n=1 \\
\text { LFB stage } 3, n=2\end{array}$ & - \\
\hline McKeith criteria [42] & $\begin{array}{l}\text { No LBD, } n=25 \\
\text { Amygdala predominant, } \\
\quad n=2\end{array}$ & $\begin{array}{l}\text { No LBD, } n=24 \\
\text { Brainstem, } n=2 \\
\text { Amygdala predominant, } n=2\end{array}$ & - \\
\hline VCING criteria [53] & Low, $n=28$ & $\begin{array}{l}\text { Low, } n=25 \\
\text { Moderate, } n=2\end{array}$ & - \\
\hline TDP-43 in AD score [30] & $\begin{array}{l}\text { Stage } 0, n=12 \\
\text { Stage } 1, n=3 \\
\text { Stage } 2, n=4 \\
\text { Stage } 3, n=2 \\
\text { Stage } 4, n=6\end{array}$ & $\begin{array}{l}\text { Stage } 0, n=21 \\
\text { Stage } 1, n=3 \\
\text { Stage } 2, n=1 \\
\text { Stage } 3, n=1 \\
\text { Stage } 4, n=2\end{array}$ & - \\
\hline CAA score [46] & $\begin{array}{l}\text { Stage } 0, n=1 \\
\text { Stage } 1, n=3 \\
\text { Stage } 2, n=12 \\
\text { Stage } 3, n=9 \\
\text { Stage } 4, n=3 \\
\text { CapCAA absent, } n=1 \\
\text { CapCAA present, } n=26\end{array}$ & $\begin{array}{l}\text { Stage } 0, n=15 \\
\text { Stage } 1, n=5 \\
\text { Stage } 2, n=8 \\
\text { CapCAA absent, } n=15 \\
\text { CapCAA present, } n=13\end{array}$ & - \\
\hline $\operatorname{MMSE}( \pm \mathrm{SD})[19]$ & $5.82(5.36)$ & $26(4.34)$ & $t_{(21)}=8.269, p=0.0001$ \\
\hline
\end{tabular}

$A D$ Alzheimer's disease, $d f$ degrees of freedom; $t$ Independent samples test, $X^{2}$ Chi -squared test, $F$ female, $M$ Male, $U$ Mann-Whitney $U$ test, $P M D$ post mortem delay, $A \beta$ amyloid-beta, NFT neurofibrillary tangle, CERAD Consortium to Establish a Registry for Alzheimer's Disease, NIA-AA National Institute on Ageing-Alzheimer's Association criteria for AD neuropathologic change, $L B$ Lewy body, VCING vascular cognitive impairment neuropathological guidelines, $C A A$ cerebral amyloid angiopathy, CapCAA capillary CAA, MMSE mini mental state examination 
of demyelination) and haematoxylin and eosin (H\&E), for visualisation of white matter artery/arteriole walls for assessment of SVD. Immunohistochemistry was performed for chronic axonal transport dysfunctional marker nonphosphorylated SMI32 (antibody SMI32) [36, 63], as well as for HP $\tau$ (antibody AT8) and A $\beta$ peptide (antibody 4G8) (details on primary antibodies and antigen retrieval protocols for immunohistochemistry are presented in Table 2). Immunopositivity was detected using the Menarini X-CellPlus HRP Detection Kit (Menarini Diagnostics, WinnershWokingham, UK) with 3,3 diaminobenzidine (DAB) as a chromagen and haematoxylin as a counter stain. All histologically and immunohistochemically stained sections were subsequently dehydrated through a series of alcohols, cleared and mounted using DPX (CellPath, Powys, UK).

\section{Image analysis}

All image analysis was performed blinded to neuropathological diagnosis. Whole LFB stained sections were scanned using an Epson Perfection V700 scanner (dual lens system) and monochrome images were uploaded into Image-Pro Plus software program (Media Cybernetics Inc, USA; version 6.3). White matter area was manually delineated from the cortical ribbon using the freehand selection tool (Fig. 1a) and total white matter area recorded (Fig. 1ai). The WML area was identified based on a defined reduction in grey colour that is clearly differentiated from the surrounding normal appearing white matter (NAWM) with the naked eye, and was confirmed by the 'bubbly' like appearance and loosening of tissue under microscopic examination [54]. To differentiate between the WML and NAWM, the 8-bit grey scale threshold was manually adjusted to select only the WML area (Fig. 1aii). The percentage area of WML per total white matter area was calculated and expressed as percentage WML area (WMLA) to obtain a measure of overall WML severity. The integrated optical density (IOD) of the LFB stain was measured. The IOD is the amount of light able to transmit through a sample and represents a measure of the intensity of histological staining. In Image Pro Plus a pixel value of 0 represent black and 255 represents white, therefore, a higher value signifies a greater amount of light transmission, i.e. a lighter stain, which, regarding LFB staining, indicates a reduction of myelin. Three images from the WML and three images from the NAWM were randomly captured at $200 \times$ magnification using a Nikon 90i microscope and uploaded on Image-Pro Plus. The mean IOD per pixel was recorded for each image and a subsequent mean IOD per pixel for WML and NAWM per case were calculated.

On LFB stained sections, the WMLA was identified macro- and microscopically and delineated by hand using a permanent marker pen to clearly differentiate between

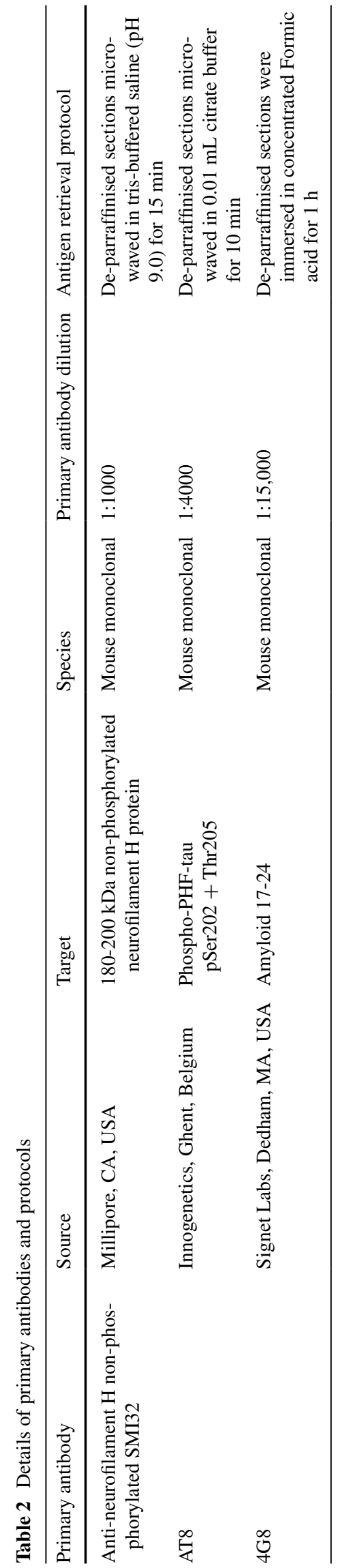



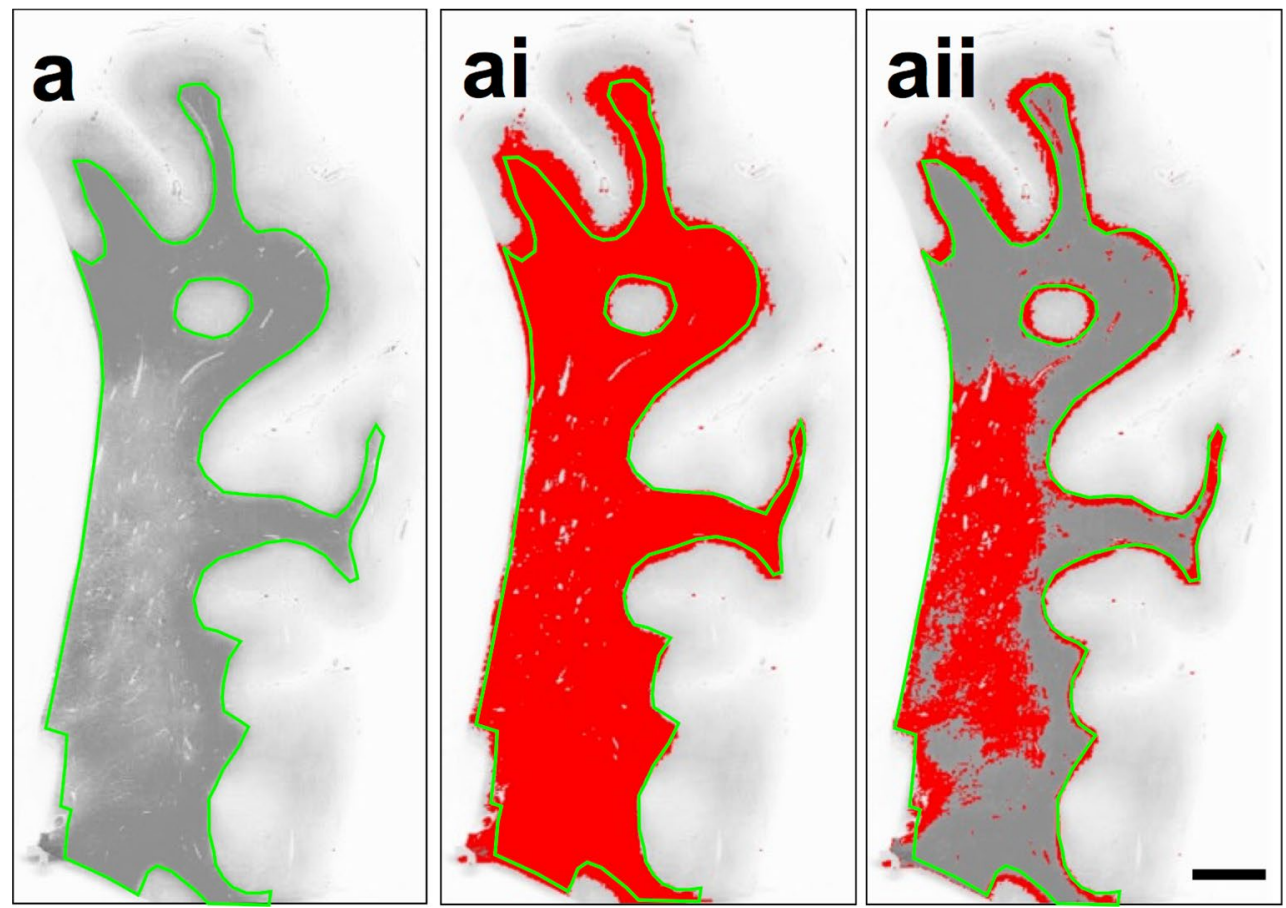

Fig. 1 a LFB stained sections were scanned and monochrome images were uploaded into Image-Pro Plus software program where the white matter was manually delineated to create a region of interest (green line). ai Using manual adjustment of the 8-bit grey scale threshold, total white matter area measured within the region of inter- est only. aii Using manual adjustment of the 8-bit grey scale threshold the WML was measured. Percentage area of WML per total white matter area was calculated and is expressed in the manuscript as WML area (WMLA). Scale bar $1 \mathrm{~cm}$, valid for a-aii
WML and NAWM. This delineated section was subsequently used to identify the corresponding WMLA in the adjacent Bielschowsky and SMI32 stained sections (Fig. 2a). On both Bielschowsky and SMI32 stained sections, $3 \times 3$ single images at $200 \times$ magnification were captured in WMLA and then combined to yield one large image representing an area of $1.7 \mathrm{~mm}^{2}$. This procedure was performed five times in each WML and NAWM to give a total of ten large images representing an area of $1.7 \mathrm{~cm}^{2}$ per section (Fig. 2b-bi). Using NIS elements version 3.0 (Nikon, Surrey, UK), individual and standardized Red Green Blue (RGB) thresholds for Bielschowsky's staining and SMI32 immunoreactivity (IR) (axonal swellings and ovoids (Fig. 2bii)) were applied to the large images (Fig. 2biii-biv). If necessary, large images were subjected to manual setting of regions of interest to exclude vessels and perivascular spaces and artefacts (Fig. 2biii, white arrow). For the Bielschowsky's staining, the RGB threshold was manually adjusted until all visible axons were included. For SMI32-IR, RGB intensity values for binary layer pixels were set as follows; R14-168, G4-158, B0-53. The area covered by Bielschowsky's stain was measured and its percentage of the total measured area calculated and expressed as Bielschowsky's area (BiA). As for Bielschowsky's stain the percentage area covered by SMI32-IR was determined, but to adjust for overall axonal density SMI32-IR percentage areas were first divided by $\mathrm{BiA}$ and multiplied by 100 and the resulting values are expressed as SMI32-IR. For both BiA and SMI32-IR mean regional values were calculated for the WMLA and NAWM per case.

For the quantification of cortical protein aggregates, four areas of parietal cortical tissue were selected on AT8 and 4G8 immunostained tissue sections. The four parietal cortex sample areas included sulci, midsection and gyri to yield an accurate mean measure of cortical pathological burden as protein aggregates have been shown to be highest in the sulcus and lowest in the gyral tip [20] (Fig. 3a-ai). At each cortical location, $3 \times 3$ single images were captured at $200 \times$ magnification and combined into one large image as previously described. If necessary large images were subjected to manual setting of regions of interest to exclude white matter and meningeal structures. Standardized RGB thresholds were applied separately for AT8 and 4G8 (Fig. 3aii). RGB intensity values for binary layer pixels were set as follows; AT8: R25-170, G27-156, B11-126; 4G8: R50-180, G20-168, B8-139. In addition, we set a size restriction threshold for the assessment of $4 \mathrm{G} 8$, which excluded the measurement of immunoreactive signals with an area below $100 \mu \mathrm{m}^{2}$; this was necessary to ensure that physiological APP that is stained with 4G8 antibody was 

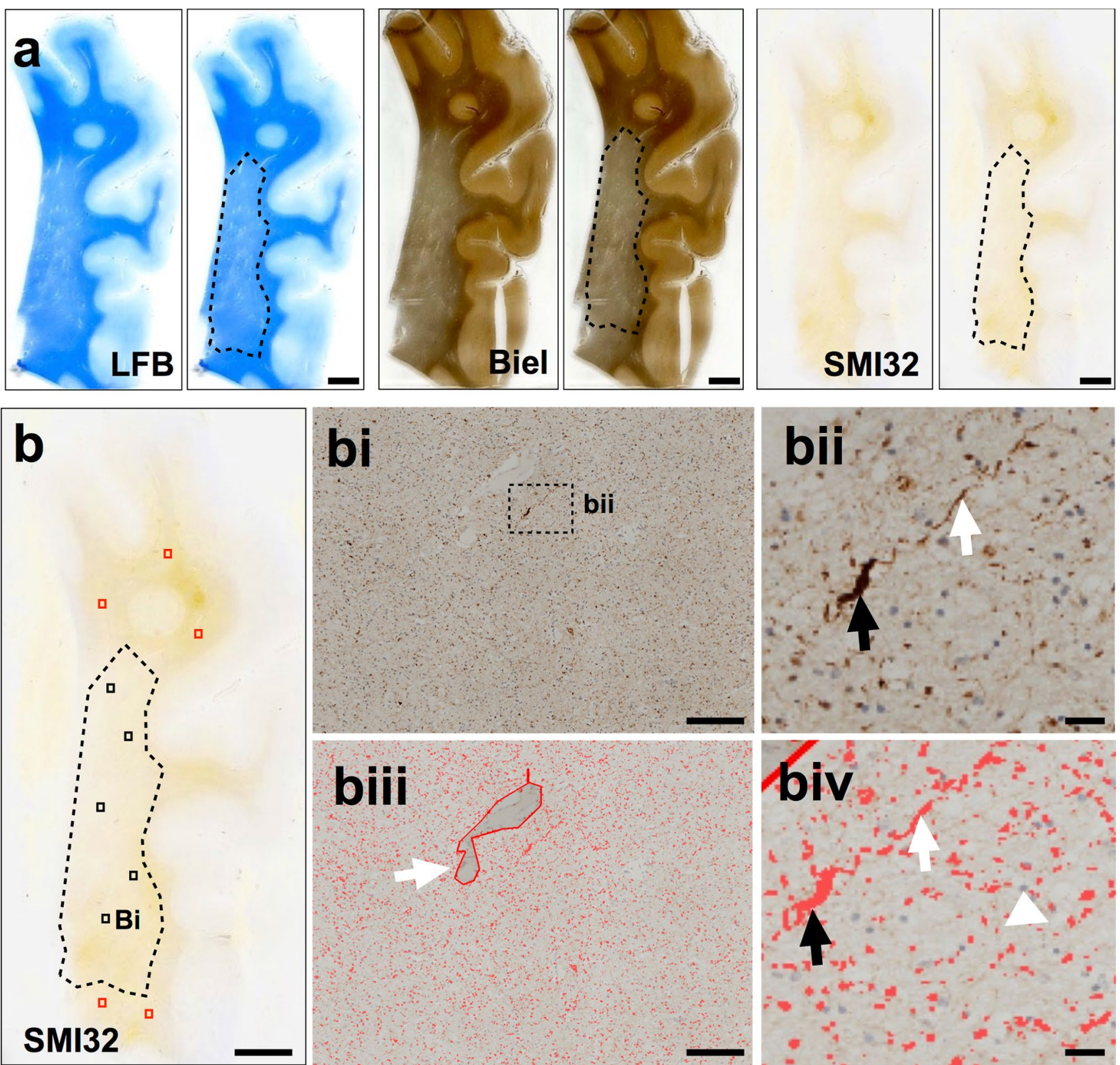

\section{biii}

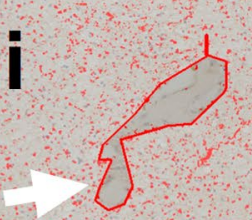

Fig. 2 a WML were identified on LFB stained sections of parietal tissue and delineated from the NAWM by hand. This was used to identify the same WMLA on serial sections stained with Bielschowsky's silver stain and SMI32. b A SMI32 stained section of parietal tissue indicating the five randomly selected areas for image capture in both the WMLA (black boxes) and NAWM (red boxes). bi $3 \times 3$ large image acquisition of SMI32-IR in WMLA. bii Magnified photomicroimage of SMI32 axonal positive pathology including discontinuous lines (white arrow) and end-bulbs axonal spheroid (black arrow). biii Image bi with applied bespoke SMI32 threshold

not included in the measurement. The percentage areas covered by AT8 and 4G8 immunoreactivity were measured and the mean values for the four sample areas were calculated and are expressed as AT8-IR and 4G8-IR, respectively.

including an example of artefact removal (white arrow). biv is image bii indicating discontinuous lines (white arrow) and end bull axonal spheroid (black arrow) with applied SMI32 threshold. Cellular nuclei were excluded from assessment (white arrow head). Mean area covered by IR was stated as a percentage of the total image area and the respective values are expressed as SMI32-IR. $L F B$ luxol fast blue, Biel Bielschowsky's silver stain, WMLA white matter lesion area, $N A W M$ normal appearing white matter, $I R$ immunoreactivity. Scale bar $50 \mathrm{~mm}$, valid for all images in image a and image $\mathbf{b} ; 100 \mu \mathrm{m}$, valid for bi, biii; $50 \mu \mathrm{m}$, valid for bii, biv

Sclerotic index (SI) is a surrogate marker of SVD severity. SI measurements were performed on H\&E stained parietal tissue sections. SI was calculated using the formula SI $=1-$ (internal diameter/external 

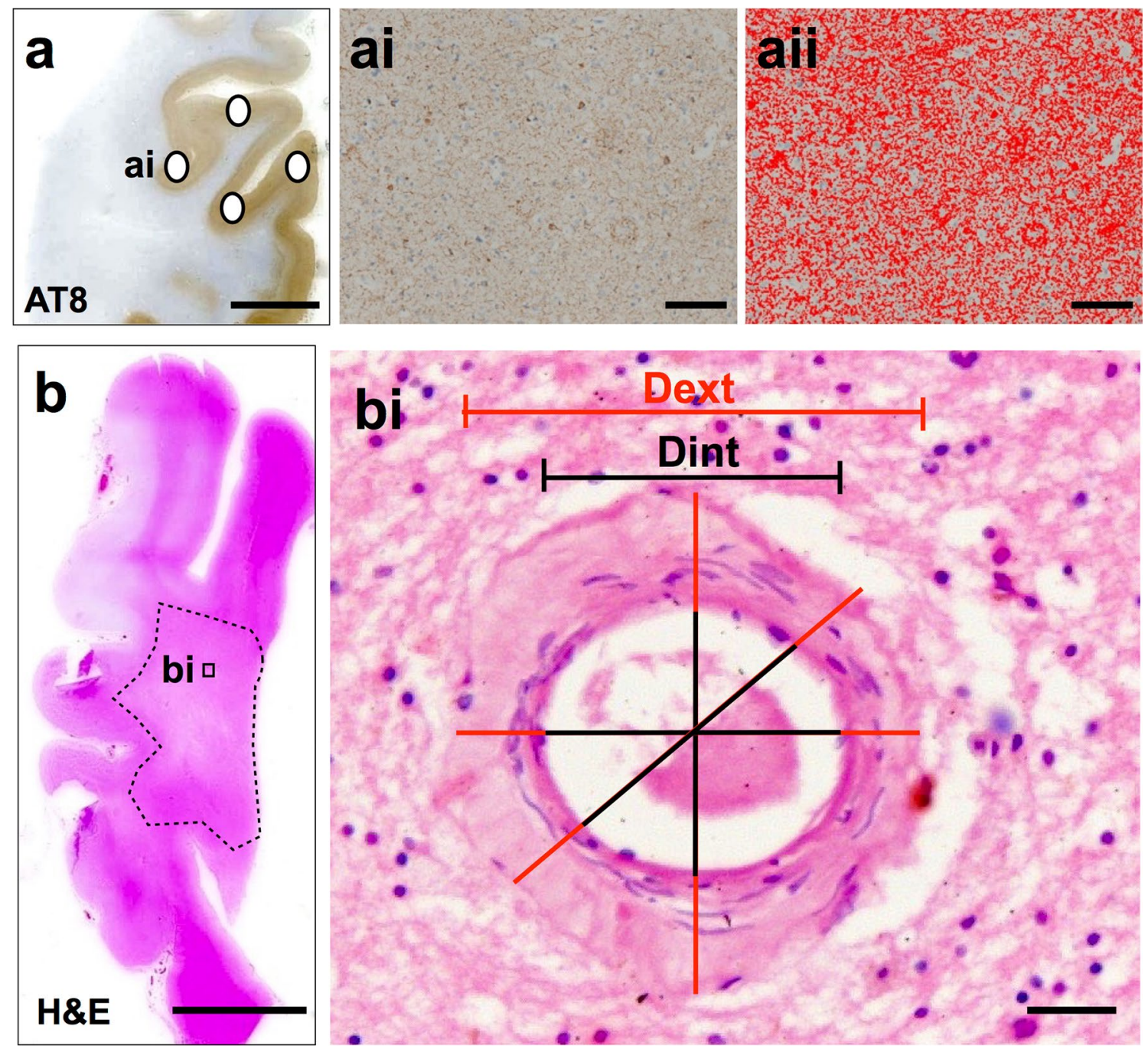

Fig. 3 a AT8 stained parietal section indicating the four sample areas. ai $3 \times 3$ large image acquisition of cortex with AT8-IR. aii Image ai with applied bespoke threshold for AT8-IR only. Mean area covered by IR was stated as a percentage of the total image area and the respective values are expressed as AT8-IR. b H\&E stained section of parietal tissue with deep white matter indicated (dashed line). Microphotoimages of up to eight individual white matter vessels were captured from the white matter for SI assessment. bi A microphotoimage of a white matter arteriole. SI was calculated using VasCalc software; [66] the internal and external diameters were measured three times to yield a SI value a mean SI value was calculated per section. IR immunoreactivity, $S I$ sclerotic index, Dext external diameter, Dint internal diameter. Scale bar $1 \mathrm{~cm}$, valid for images in $\mathbf{a}, \mathbf{b}$; $100 \mu \mathrm{m}$, valid for ai, aii; $50 \mu \mathrm{m}$, valid for bi

\section{Biochemistry}

Frozen $\left(-80^{\circ} \mathrm{C}\right)$ coronal slices incorporating the parietal lobe were brought to $-20{ }^{\circ} \mathrm{C}$ in a freezing cabinet and sub-dissected to remove Brodmann area 40/22 and its adjoining white matter. $10 \mu \mathrm{m}$ frozen sections were cut and fixed in $10 \%$ buffered aqueous formaldehyde solution for $1 \mathrm{~h}$ and then histochemically stained with LFB as described above. On the slide, the WML was identified microscopically and delineated by hand to clearly differentiate between WML and NAWM and used to guide frozen tissue extraction. Approximately $250 \mathrm{mg}$ of tissue 
was removed from each WML and the NAWM. Lysis buffer containing $0.2 \mathrm{M}$ tetraethyl ammonium bicarbonate, pH 7.2 (TEAB; Sigma, UK) and protease inhibitor tablets ( 1 tablet per $10 \mathrm{ml}$; Complete, Roche, Burgess Hill, UK) were added to tissue samples at a $1 \mathrm{mg} / 1 \mathrm{ml}$ ratio. Samples were then homogenised using an Ultraturrax T10 homogeniser (S10N-5G $5 \mathrm{~mm}$ diameter probe; $30,000 \mathrm{rpm}$ ), aliquoted at $500 \mu 1$ with $5 \mu 1$ of $1 \%$ SDS and stored at $-80{ }^{\circ} \mathrm{C}$ until required.

Total protein concentration was determined by Bradford assay and final protein concentration for all samples was adjusted to $3 \mathrm{mg} / \mathrm{ml}$. Using commercially available sandwich enzyme-linked immunosorbent assays (ELISA) kits, five proteins were measured in both WML and NAWM tissue samples, including Wallerian degeneration markers calpain2 (CAPN2; large catalytic subunit $(80 \mathrm{kDa})$ found in myelinated axons), calpain specific inhibitor calpastatin (CASP) [21], calpain specific spectrin breakdown product 145 (SBDP145) [68], and ischemia markers myelin-associated glycoprotein (MAG; myelin sheath protein, expressed only in the myelin loops and highly vulnerable under ischemic conditions) and proteolipid protein (PLP; myelin sheath protein that is abundant throughout the sheath and stable under ischemic conditions) [6] to calculate the MAG:PLP as an indication of pre-mortem white matter ischemia [6]. Details regarding ELISA kits are presented in Table 3. ELISA protocols were followed according to manufactures instructions. Briefly, working standards and samples were prepared/diluted as required. $100 \mu \mathrm{l}$ of standard and sample were pipetted into wells of the 96-well coated microplates and incubated for $2 \mathrm{~h}$ at $37^{\circ} \mathrm{C}$. Liquid was removed and $100 \mu \mathrm{l}$ of biotin-antibody was applied to each well and incubated for $1 \mathrm{~h}$ at $37^{\circ} \mathrm{C}$. Wells were then aspirated and washed three times with wash buffer before $100 \mu 1$ HRP-avidin solution was applied to each well and incubated for $1 \mathrm{~h}$ at $37{ }^{\circ} \mathrm{C}$. Wells were aspirated and washed a further five times and $90 \mu 1$ of TMB substrate was applied to each well and incubated for $30 \mathrm{~min}$ at $37^{\circ} \mathrm{C}$. The reaction was stopped with $50 \mu \mathrm{l}$ of stop solution per well and absorbance was read at appropriate wavelength within 5 min in a FLUOstar Omega multi-detection microplate reader (BMG Labtech, Aylesbury, UK).

\section{Statistics}

The Statistical Package for Social Sciences software (SPSS ver. 21) was used for statistical evaluation. Variables were tested for normality using the Shapiro-Wilk test and visual inspection of variable histograms. Differences in related variables (WML vs. NAWM) were assessed using non-parametric Wilcoxon test. Group effects were assessed using either non-parametric (Mann-Whitney $U$ ) or parametric (independent samples $t$ test) procedures. Where appropriate, Spearman's $(\rho)$ and Pearson's $(r)$ correlation coefficients were used to assess associations between variables. Exploratory stepwise linear regression analyses were also conducted to investigate pathological predictors of WMLA and WML pathology.

\section{Results}

No significant differences were observed in age or postmortem delay between $\mathrm{AD}$ and control groups. $\mathrm{AD}$ cases had significantly higher levels of AD neuropathological change and significantly lower MMSE scores compared to controls (Table 1). Fifty cases contained at least one WML and all 55 cases underwent NAWM assessment.

\section{Histological characteristics of WML and NAWM}

Mean values for WMLA, BiA, LFB-IOD and SMI32-IR for both WML and NAWM are presented in supplementary Table 1. Briefly, with regards to the whole cohort, when compared to NAWM tissue, WML tissue had significantly lower $\operatorname{BiA}(p<0.0001)$, indicating axonal loss, significantly higher LFB-IOD values $(p<0.0001)$, indicating demyelination, as well as significantly higher SMI32IR $(p<0.01)$, indicating increased chronic axonal transport dysfunction. WMLA was significantly greater in $\mathrm{AD}$ compared to controls $(p<0.05)$, but SI values did not differ between these groups.

Table 3 Details of ELISA kits used for detection of proteins in frozen tissue samples

\begin{tabular}{llllcr}
\hline Protein & ELISA Kit & & \multirow{2}{*}{ Sample dilution } & Standard curve (ng/ml) & OD wavelength \\
\cline { 2 - 3 } & Cat \# & Description & & \\
\hline CAPN2 & CSB-E17822h & Human CAPN2 ELISA kit, Cusabio & Neat samples & $2.5-0.039$ & 450 and 540 nm \\
CAST & CSB-E17483 h & Human CAST ELISA kit, Cusabio & $1: 50$ & $100-1.56$ & 450 and 540 nm \\
SBDP145 & CSB-EQ028022HU & Human SBDP145 ELISA kit Cusabio & Neat samples & $40-0.625$ & 450 and 540 nm \\
MAG & CSB-E17901h & Human MAG ELISA Kit, Cusabio & Neat samples & $20-0.1$ & 450 and 540 nm \\
PLP & MBS266920 & Human PLP ELISA Kit, MyBioSource & Neat samples & $10-0.156$ & $450 \mathrm{~nm}$ \\
\hline
\end{tabular}


Associations between WML severity and axonal loss, demyelination and axonal transport

We examined the relationship between WMLA and BiA, LFB-IOD, and SMI32-IR of both WML and NAWM. In AD cases, WMLA negatively correlated with both WMLBiA $(\rho=-0.648, p=0.0001$; Fig. 4ai $)$ and NAWMBiA $(\rho=-0.334, p=0.044$; Fig. 4aii). In contrast, no correlations were observed in control cases (WML-BiA, $p=0.436$; NAWM-BiA, $p=0.365$; Fig. 4ai-ii), indicating that increasing WML severity was significantly associated with axonal loss in the WML and surrounding NAWM in $\mathrm{AD}$ cases but not in controls. In both $\mathrm{AD}$ and controls, WMLA correlated with both WML-LFB-IOD (AD, $\rho=0.755, p=0.0001$; controls, $\rho=0.413, p=0.016$; Fig. 4bi) and NAWM-LFB-IOD (AD, $\rho=0.445, p=0.01$; $\rho=0.407, p=0.018$; Fig. 4bii), indicating increasing WML severity was associated with demyelination in the WML and surrounding NAWM in both AD and control cases. Negative correlations were observed between BiA and LFB-IOD in both WML $(\rho=-0.528, p=0.004)$ and NAWM $(\rho=-0.430, p=0.013)$ in AD cases only (controls: WML, $p=0.133$; NAWM, $p=0.073$ ) (Fig. 4ci-ii). This indicates that in AD cases loss of myelin is primarily due to loss of myelinated axons, unlike control cases that exhibited no such association. No correlations were revealed between WML-SMI32-IR or NAWM-SMI32IR and WMLA in either AD (WML, $p=0.390$; NAWM, $p=0.186$ ) or control cases (WML, $p=0.091$; NAWM, $p=0.402$ ). To investigate whether WML-BiA or WMLLFB-IOD independently predicted WMLA, stepwise linear regression analysis was performed. In the $\mathrm{AD}$ group both WML-BiA $(\beta=-0.375, p=0.013)$ and WML-LFB-IOD $(\beta=0.761, p=0.0001)$ significantly predicted WMLA (model $R^{2}=0.688, F_{(2)}=23.18, p<0.001$ ). In contrast for controls, only WML-LFB-IOD was found to be a significant predictor of WMLA (model $R^{2}=0.332, F_{(2)}=12.41$, $p<0.01 ; \beta=0.601, p=0.002)$ and not WML-BiA $(p=0.957)$.

Influence of cortical neurodegenerative pathology, SVD and CAA on WML severity, axonal loss, demyelination and axonal transport

We investigated whether cortical neurodegenerative ADpathologies and SVD were associated with white matter pathological changes. A correlation matrix for the whole cohort, as well as separately for $\mathrm{AD}$ and controls, is presented in supplementary Table 2. No correlations were seen when statistical analysis was performed separately for $\mathrm{AD}$ and controls. However, with regards to the whole cohort, which is inclusive of Braak stage 0-VI and Thal A $\beta$ Phases 1-5, WMLA correlated with AT8-IR $(\rho=0.284$, $p=0.022)$ but not 4G8-IR $(p=0.072)$, SI $(p=0.451)$ or CAA $(p=0.185)$. WML-LFB-IOD was also correlated with AT8-IR $(\rho=0.289, p=0.002)$ but not 4G8-IR $(p=0.147), \operatorname{SVD}(p=0.433)$ or CAA $(p=0.492)$. No correlations were observed between WML-BiA and any neurodegenerative pathology, SI or CAA. Finally, we correlated WML-SMI32-IR with AT8-IR, 4G8-IR, SI and CAA to determine if AD-associated pathologies or SVD was involved in chronic axonal transport dysfunction; however, no significant correlations were yielded with any pathology (AT8, $p=0.274 ; 4 \mathrm{G} 8, p=0.153$; SI, $p=0.314$; $\mathrm{CAA}, p=0.916)$.

\section{Wallerian degeneration and ischemia}

Firstly, we investigated the regulation and activation of the protease calpain2; calpain2 was increased in the WML compared to NAWM ( $p=0.073$ ) and calpastatin (calpain2 inhibitor) levels were decreased in the WML compared to NAWM $(p=0.10)$ indicating corresponding down regulation of calpastatin and up regulation of calpain2. A correlation between mean values of calpain2 and SBDP145 ( $\rho=0.521, p=0.0001)$ was observed, indicating specific calpain2 activity.

Calpain2 was significantly higher in both the WML $(p=0.022)$ and NAWM tissue $(p=0.005)$ of AD cases compared to controls (Fig. 5a). No significant difference was revealed with WML- or NAWM MAG values between AD and control cases (WML, $p=0.457$; NAWM, $p=0.460$; Fig. 5b), in contrast to WML- and NAWM PLP that was found to be significantly reduced in AD cases (WML, $p=0.0001$; NAWM, $p=0.007$; Fig. 5c). The MAG:PLP was significantly lower in WML tissue of control cases compared to AD cases ( $p=0.02$; Fig. $5 \mathrm{~d}$ ), however, no significant differences was seen in NAWM tissue between $\mathrm{AD}$ and controls $(p=0.221)$.

With regards to the whole cohort that is inclusive of Braak NFT stage $0-\mathrm{VI}$ and Thal A $\beta$ Phases 1-5, we examined correlations of WML measures of calpain2, MAG, PLP and MAG:PLP with pathological measures of cortical neurodegenerative AD-pathologies, SVD and CAA to investigate the pathological relationships of white matter changes. Calpain2 correlated with AT8IR $(\rho=0.369, p=0.01)$ and 4G8-IR $(p=0.012)$, but not SI $(p=0.184)$ or CAA $(p=0.433)$. No correlations were seen between MAG values and AT8-IR ( $p=0.163)$, 4G8-IR $(p=0.256)$, SI $(p=0.210)$ or CAA $(p=0.590)$. PLP negatively correlated with both AT8-IR $(\rho=-0.488$, $p=0.001)$ and 4G8-IR $(\rho=-0.401, p=0.004)$, but not with SI $(p=0.273)$ or CAA $(p=0.536)$. MAG:PLP correlated with both AT8-IR ( $\rho=0.347, p=0.028)$ but not 4 G8-IR $(p=0.076)$, SI $(p=0.705)$ or CAA $(p=0.453)$. 

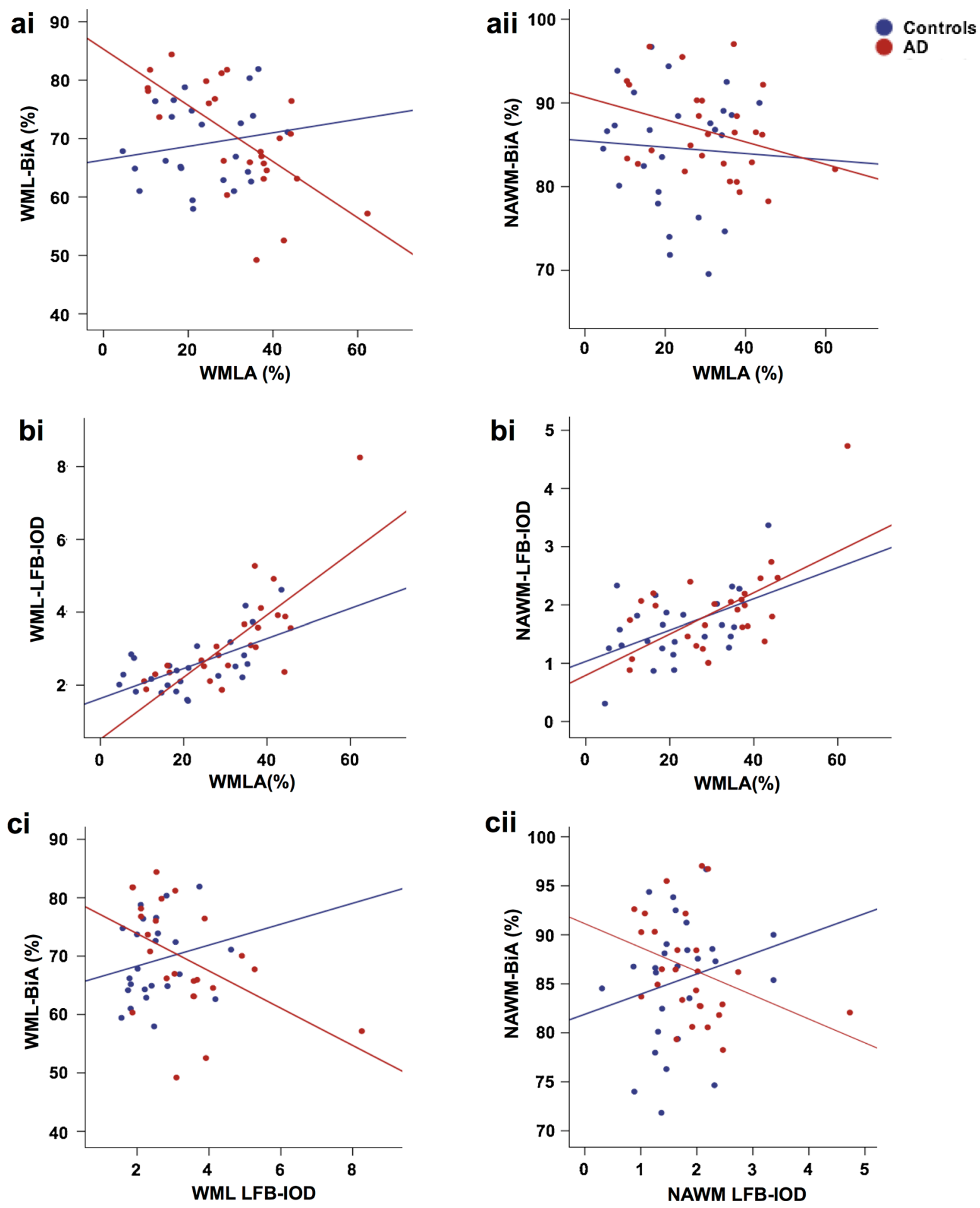

Fig. 4 Scatter graphs show; ai negative correlations between WMLA and WML-BiA in AD cases only. aii Negative correlations between WMLA and NAWM-BiA in AD cases only. bi A positive correlation between WMLA and WML- and bii NAWM- LFB-IOD was seen in both $\mathrm{AD}$ and control cases. ci a negative correlation between WML$\mathrm{BiA}$ and WML-LFB-IOD in AD cases only. cii A negative correlation

between NAWM-BiA and NAWM-LFB-IOD was seen in AD cases only. $p$ values and associated correlation coefficients are shown in main text. $W M L$ white matter lesion, $N A W M$ normal appearing white matter, WMLA white matter lesion area, BiA Bielschowsky's area, $L F B-I O D$ luxol fast blue integrated optical density 

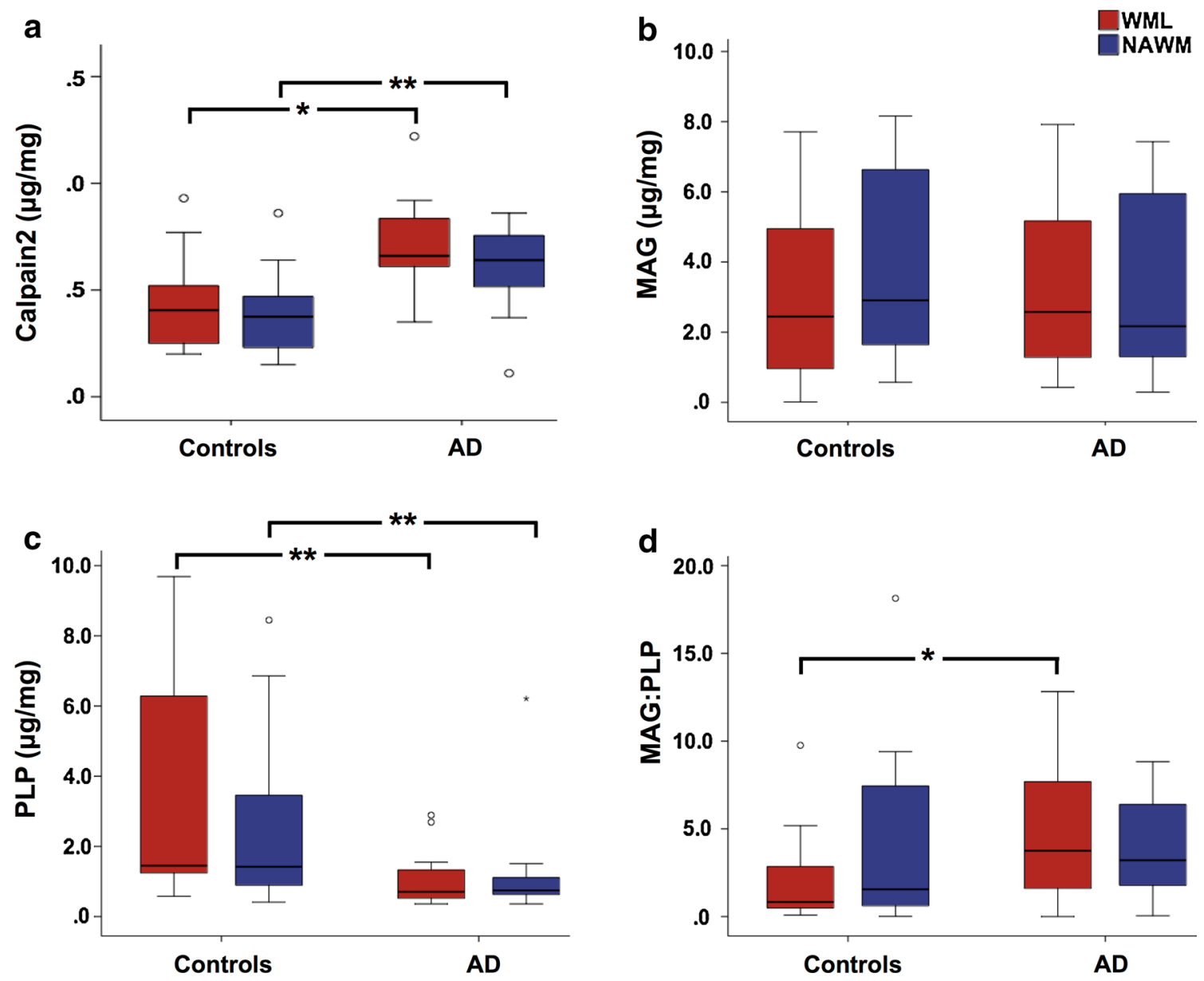

Fig. 5 Box plots show; a Calpain2 was significantly higher in the WML tissue of AD cases compared to controls. b No significant difference was seen in WML-MAG between AD and control cases. c PLP was significantly lower in the WML tissue of AD cases com-

pared to controls. d MAG:PLP was significantly lower in the WML tissue of control compared to $\mathrm{AD}$ cases. $* p<0.05$; ***p $<0.001$. Exact $p$ values are shown in main text. $A D$ Alzheimer's disease, $M A G$ myelin associated glycoprotein, $P L P$ proteolipid protein

No correlations were seen when statistical analysis was performed separately for $\mathrm{AD}$ and controls.

\section{Discussion}

Here, for the first time, we reveal differences in the underlying pathology and molecular signatures of parietal WML between $\mathrm{AD}$ and non-demented elderly that indicate differing aetiologies. Pathologically, increasing severity of WML in AD is associated with both axonal loss and demyelination, in contrast to non-demented individuals in which WML are associated with demyelination only. Biochemical analysis indicated an increase in calpain2 levels in the white matter of $\mathrm{AD}$ cases, which is suggestive of increased Wallerian degeneration that is associated with increasing cortical burden of AD-related pathologies but not with SVD. Furthermore, MAG:PLP values were reduced in the WML tissue of control cases, indicating hypoperfusion.
Overall, our data indicate that parietal WML (WMH) seen in $\mathrm{AD}$ are associated with demyelination and axonal loss as a result of degenerative axonal loss and not ischemic damage as seen in normally aged controls.

The pathogenesis of WML is often being assumed to be the result of SVD; hence, the detection of in vivo WMH frequently supports the diagnosis of $\mathrm{VCI} / \mathrm{VaD}$. However, ample evidence has indicated that WML in AD may well be the result of degenerative axonal loss due to Wallerian degeneration triggered by cortical AD pathology. Indeed, we found that WML were significantly more severe in the $\mathrm{AD}$ cases compared to the non-demented cases, in agreement with findings in previous studies [8, 40, 49]. Our thorough, quantitative neuropathological investigations revealed that in $\mathrm{AD}$ axonal loss and demyelination, in both the WML itself and the surrounding NAWM, were associated with and are a predictor of increasing severity of WML. This is in contrast to non-demented cases where only demyelination predicts and associates with WML 
severity. These pathological changes were further supported by our biochemical analysis of WML tissue, which showed a significant decrease in PLP levels in AD, indicative of axonal atrophy, as well as equal loss of MAG levels between $\mathrm{AD}$ and control brains, signifying demyelination in both groups. Both the pathological and biochemical data indicate that increased myelin loss in the AD group is likely due to severe axonal atrophy. A previous neuropathological study investigated differences in myelin and axonal densities of WML between AD and controls cases and found no differences; however, this was based on WML from any brain region and was not specific to the posterior or medial temporal regions [23]. We can, therefore, report for the first time differences in the pathological composition WML between $\mathrm{AD}$ cases and controls in the parietal white matter.

Degenerative axonal loss in AD can occur as a consequence of Wallerian degeneration [15, 29, 65] where calpain is the primary protease involved in axonal destruction [38]. Our data revealed that calpain levels were significantly increased in WML in AD compared to controls and were associated with increasing cortical HP $\tau$ and $A \beta$ pathology burden but not with SVD. Calpain activation is thought to be triggered by anterograde axonal transport disruption and/or blockage [12, 39], which are a common early feature in AD. Axonal SMI32 pathology, which is an indicator of chronic axonal transport dysfunction [48], was found to be significantly higher in WML compared to NAWM indicating disruption of axonal transport in the WML area. However, no difference in the amount of SMI32 pathology was found between $\mathrm{AD}$ and controls, and therefore, we cannot conclude whether axonal transport dysfunction is the instigator of increased levels of calpain in the $\mathrm{AD}$ group.

WML in the control cases, that primarily consisted of demyelination, were found to be the result of ischemia as indicated by a significant reduction in the MAG:PLP ratio. Barker and colleagues had previously measured the MAG:PLP ratio in the parietal white matter of $\mathrm{AD}$ and control cases and found no respective differences. However, they did not distinguish specifically between NAWM and WML [6], hence the data from Barker and colleagues is in agreement with our findings in the NAWM. Only in the WML tissue of control cases was the MAG:PLP ratio significantly lower compared to WML seen in AD cases indicating that in AD WML were not primarily associated with hypoxia. Ischemia has long been associated as the primary cause of WML and WMH in both normal ageing and dementia [24, 45, 47]; however, with the addition of more sensitive and reliable biochemical measures of ischemic change [6] we could now clarify that ischemia is not the only potential cause for WML and it appears unlikely to be the major cause for posterior WML in AD. Naturally, SVD in $\mathrm{AD}$ cases may have an influence on the development of
WML; however, our data indicates that the respective influence of HP $\tau$ pathology exceeds that of SVD.

Cortical HP $\tau$ pathology was associated with both WML severity and demyelination, while the latter were not associated with arteriopathy in cases showing considerable cortical $\mathrm{HP} \tau$. While no direct pathological associations between HP $\tau$ or A $\beta$ pathology burden with decreased axonal density were revealed, a decrease in WML PLP levels (indicative of axonal atrophy) was associated with increasing $\mathrm{HP} \tau$ pathology. One may speculate that the increasing burden of cortical $\mathrm{HP} \tau$ pathology is a trigger of Wallerian degeneration. Indeed, cortical HP $\tau$ has been implicated as an instigator of degenerative axonal loss in AD. Previous quantitative neuropathological [40], longitudinal community-based [52] and biomarker studies [60] have indicated an association between HP $\tau$ and the development of WMH in the absence of SVD [17, 35, 60]. Moreover, in Pick's disease, which is a primary tauopathy, white matter degeneration and demyelination was significantly more severe in white matter regions proximal to severe cortical HP $\tau$ pathology [58]. However, the exact underlying mechanisms of HP $\tau$ associated axonal degeneration are still unclear and further mechanistic investigations are warranted.

It is important to note that our study focused specifically on WML located in the parietal region. Studies have indicated that in non-demented patients WML/WMH are more prevalent in the frontal region compared to patients with $\mathrm{AD}[61,64]$ and are attributed to cerebrovascular disease $[61,62]$. The difference in aetiology could be attributed to the posterior and MTL regions being affected early with $\mathrm{HP} \tau$ pathology deposition [10]. Differentiation of the aetiology and pathological/biochemical signatures of WML/ WMH from the anterior and posterior regions of the brain is warranted for diagnostic clarification.

CAA was not associated with any measure of WML pathology or molecular measure of Wallerian degeneration or ischemia in agreement with a previous neuropathological and imaging study [56]. Due to the high prevalence of CAA in AD statistical associations between CAA and WML may possibly be caused by the presence of concomitant cortical AD pathology, specifically HP $\tau$ pathology.

Understanding the underlying mechanisms of WML/ WMH pathogenesis is crucial for the accurate diagnosis and therapeutic interventions of patients with cognitive impairment, in particular, as current clinical criteria for $\mathrm{VaD} / \mathrm{VCI}$ [22] and mixed $\mathrm{AD} / \mathrm{VaD}$ [16] are based on the detection of WMH as surrogate marker for SVD. Our findings provide further evidence that the underlying aetiology of WML in AD is not restricted to SVD and may indeed be indicative for AD pathology. If WML are invariably used as a surrogate biomarker for SVD, as suggested by current clinical guidelines [16, 22], this will bias cohort stratification in clinical trials, result in 
misdiagnosis of patients, and have a detrimental impact on the choice of therapeutic interventions, e.g. AD patients being misdiagnosed with $\mathrm{VaD}$ would not receive acetylcholinesterase inhibitors as recommended for managing mild to moderate AD [18]. As mentioned previously, our study focused on parietal WML and prior work suggests that the aetiology of WML differs by anatomical location [34], hence, further imaging studies that also involve new in vivo imaging of $\mathrm{HP} \tau$ [11] and $\mathrm{A} \beta$ [32] pathology and integrate anatomical location, pathophysiology and impact on cognition are warranted. Finally, our results call for more detailed neuropathological evaluation of cerebral white matter injury in dementia. Current approaches do not adequately assess this important tissue and understanding the pathophysiology of white matter damage is not only important to clinical phenotype, but may open avenues to new therapeutics to modify the course of degenerative dementias.

In conclusion, the pathological and biochemical signatures of parietal WML/WMH differ between AD and non-demented individuals, and in $\mathrm{AD}$ the pathogenesis of posterior WML/WMH is associated with degenerative axonal changes probably occurring secondary to cortical AD-pathology. These novel findings support previous neuroimaging studies that indicate Wallerian degeneration-associated axonal damage may be a cause of posterior $\mathrm{WMH}$ in $\mathrm{AD}$. Further elucidation of the role of $\mathrm{AD}$ pathologies in the pathogenesis of WML/WMH is paramount for accurate diagnosis and improved stratification of patients for clinical trials.

Acknowledgements We are very grateful to the individuals who kindly donated their brains to the Newcastle Brain Tissue Resource. We thank Mrs. Lynne Ramsay, Mrs. Ros Hall, Dr. Craig Parker and Mrs. Claire Kolenda for their excellent technical assistance.

\section{Compliance with ethical standards}

Funding The research was supported by the Alzheimer's Society (Grant Number: AS-PG-2013-011). Tissue for this study was provided by the Newcastle Brain Tissue Resource, which is funded in part by a grant from the UK Medical Research Council (G0400074) and by Brains for Dementia research, a joint venture between Alzheimer's Society and Alzheimer's Research UK.

Conflict of interest The authors declare that they have no conflict of interest.

Open Access This article is distributed under the terms of the Creative Commons Attribution 4.0 International License (http://creativecommons.org/licenses/by/4.0/), which permits unrestricted use, distribution, and reproduction in any medium, provided you give appropriate credit to the original author(s) and the source, provide a link to the Creative Commons license, and indicate if changes were made.

\section{References}

1. Acosta-Cabronero J, Williams GB, Pengas G, Nestor PJ (2010) Absolute diffusivities define the landscape of white matter degeneration in Alzheimer's disease. Brain 133:529-539

2. Agosta F, Pievani M, Sala S, Geroldi C, Galluzzi S, Frisoni GB et al (2011) White matter damage in Alzheimer disease and its relationship to gray matter atrophy. Radiology 258:853-863

3. Amlien IK, Fjell AM, Walhovd KB, Selnes P, Stenset V, Grambaite R et al (2013) Mild cognitive impairment: cerebrospinal fluid tau biomarker pathologic levels and longitudinal changes in white matter integrity. Radiology 266:295-303

4. Attems J, Jellinger KA (2004) Only cerebral capillary amyloid angiopathy correlates with Alzheimer pathology — a pilot study. Acta Neuropathol 107:83-90

5. Barber R, Scheltens P, Gholkar A, Ballard C, McKeith I, Ince P et al (1999) White matter lesions on magnetic resonance imaging in dementia with Lewy bodies, Alzheimer's disease, vascular dementia, and normal aging. J Neurol Neurosurg Psychiatry 67:66-72

6. Barker R, Wellington D, Esiri MM, Love S (2013) Assessing white matter ischemic damage in dementia patients by measurement of myelin proteins. J Cereb Blood Flow Metab 33:1050-1057

7. Bosch B, Arenaza-Urquijo EM, Rami L, Sala-Llonch R, Junque C, Sole-Padulles C et al (2012) Multiple DTI index analysis in normal aging, amnestic MCI and AD. Relationship with neuropsychological performance. Neurobiol Aging 33:61-74

8. Bozzali M, Falini A, Franceschi M, Cercignani M, Zuffi M, Scotti G et al (2002) White matter damage in Alzheimer's disease assessed in vivo using diffusion tensor magnetic resonance imaging. J Neurol Neurosurg Psychiatry 72:742-746

9. Braak H, Del Tredici K, Rub U, de Vos RA, Jansen Steur EN, Braak E (2003) Staging of brain pathology related to sporadic Parkinson's disease. Neurobiol Aging 24:197-211

10. Braak H, Alafuzoff I, Arzberger T, Kretzschmar H, Del Tredici K (2006) Staging of Alzheimer disease-associated neurofibrillary pathology using paraffin sections and immunocytochemistry. Acta Neuropathol 112:389-404

11. Chien DT, Bahri S, Szardenings AK, Walsh JC, Mu F, Su MY et al (2013) Early clinical PET imaging results with the novel PHF-tau radioligand [F-18]-T807. J Alzheimers Dis 34:457-468

12. Coleman M (2005) Axon degeneration mechanisms: commonality amid diversity. Nat Rev Neurosci 6:889-898

13. de Lima S, Mietto BS, Paula C, Muniz T, Martinez AM, Gardino PF (2016) Rescuing axons from degeneration does not affect retinal ganglion cell death. Braz J Med Biol Res 49:e5106

14. Debette S, Markus HS (2010) The clinical importance of white matter hyperintensities on brain magnetic resonance imaging: systematic review and meta-analysis. BMJ 341:c3666

15. Duan JH, Wang HQ, Xu J, Lin X, Chen SQ, Kang Z et al (2006) White matter damage of patients with Alzheimer's disease correlated with the decreased cognitive function. Surg Radiol Anat 28:150-156

16. Dubois B, Feldman HH, Jacova C, Hampel H, Molinuevo JL, Blennow K et al (2014) Advancing research diagnostic criteria for Alzheimer's disease: the IWG-2 criteria. Lancet Neurol 13:614-629

17. Englund E (1998) Neuropathology of white matter changes in Alzheimer's disease and vascular dementia. Dement Geriatr Cogn Disord 9(Suppl 1):6-12

18. Fairbairn AF, Gould N, Kendall T, Ashley P, Bainbridge I, Bower L, et al. (2007) Therapeutic interventions for people with dementia. In: Dementia: A NICE-SCIE guideline on supporting 
people with dementia and their carers in health and social care. The British Psychological Society and Gaskell Leicester UK, pp 164-216

19. Folstein MF, Folstein SE, McHugh PR (1975) "Mini-mental state". A practical method for grading the cognitive state of patients for the clinician. J Psychiatr Res 12:189-198

20. Gentleman SM, Allsop D, Bruton CJ, Jagoe R, Polak JM, Roberts GW (1992) Quantitative differences in the deposition of beta A4 protein in the sulci and gyri of frontal and temporal isocortex in Alzheimer's disease. Neurosci Lett 136:27-30

21. Goll DE, Thompson VF, Li H, Wei W, Cong J (2003) The calpain system. Physiol Rev 83:731-801

22. Gorelick PB, Scuteri A, Black SE, Decarli C, Greenberg SM, Iadecola $C$ et al (2011) Vascular contributions to cognitive impairment and dementia: a statement for healthcare professionals from the american heart association/american stroke association. Stroke 42:2672-2713

23. Gouw AA, Seewann A, Vrenken H, van der Flier WM, Rozemuller JM, Barkhof F et al (2008) Heterogeneity of white matter hyperintensities in Alzheimer's disease: post-mortem quantitative MRI and neuropathology. Brain 131:3286-3298

24. Gouw AA, Seewann A, van der Flier WM, Barkhof F, Rozemuller AM, Scheltens P et al (2011) Heterogeneity of small vessel disease: a systematic review of MRI and histopathology correlations. J Neurol Neurosurg Psychiatry 82:126-135

25. Grinberg LT, Thal DR (2010) Vascular pathology in the aged human brain. Acta Neuropathol 119:277-290

26. Gurol ME, Irizarry MC, Smith EE, Raju S, Diaz-Arrastia R, Bottiglieri $T$ et al (2006) Plasma beta-amyloid and white matter lesions in AD, MCI, and cerebral amyloid angiopathy. Neurology 66:23-29

27. Hachinski VC, Potter P, Merskey H (1987) Leuko-araiosis. Arch Neurol 44:21-23

28. Hong YJ, Kim CM, Jang EH, Hwang J, Roh JH, Lee JH (2016) White matter changes may precede gray matter loss in elderly with subjective memory impairment. Dement Geriatr Cogn Disord 42:227-235

29. Huang J, Friedland RP, Auchus AP (2007) Diffusion tensor imaging of normal-appearing white matter in mild cognitive impairment and early Alzheimer disease: preliminary evidence of axonal degeneration in the temporal lobe. Am J Neuroradiol 28:1943-1948

30. Josephs KA, Murray ME, Whitwell JL, Parisi JE, Petrucelli L, Jack CR et al (2014) Staging TDP-43 pathology in Alzheimer's disease. Acta Neuropathol 127:441-450

31. Kantarci K, Murray ME, Schwarz CG, Reid RI, Przybelski SA, Lesnick T et al (2017) White-matter integrity on DTI and the pathologic staging of Alzheimer's disease. Neurobiol Aging 56:172-179

32. Klunk WE, Engler H, Nordberg A, Wang Y, Blomqvist G, Holt DP et al (2004) Imaging brain amyloid in Alzheimer's disease with Pittsburgh Compound-B. Ann Neurol 55:306-319

33. Lammie GA, Brannan F, Slattery J, Warlow C (1997) Nonhypertensive cerebral small-vessel disease. An autopsy study. Stroke 28:2222-2229

34. Lee DY, Fletcher E, Martinez O, Zozulya N, Kim J, Tran J et al (2010) Vascular and degenerative processes differentially affect regional interhemispheric connections in normal aging, mild cognitive impairment, and Alzheimer disease. Stroke 41:1791-1797

35. Leys D, Pruvo JP, Parent M, Vermersch P, Soetaert G, Steinling $M$ et al (1991) Could Wallerian degeneration contribute to "leuko-araiosis" in subjects free of any vascular disorder? J Neurol Neurosurg Psychiatry 54:46-50

36. Lindner M, Fokuhl J, Linsmeier F, Trebst C, Stangel M (2009) Chronic toxic demyelination in the central nervous system leads to axonal damage despite remyelination. Neurosci Lett 453:120-125
37. Litchfield S, Nagy Z (2001) New temperature modification makes the Bielschowsky silver stain reproducible. Acta Neuropathol 101:17-21

38. Ma M (2013) Role of calpains in the injury-induced dysfunction and degeneration of the mammalian axon. Neurobiol Dis 60:61-79

39. Ma M, Ferguson TA, Schoch KM, Li J, Qian Y, Shofer FS et al (2013) Calpains mediate axonal cytoskeleton disintegration during Wallerian degeneration. Neurobiol Dis 56:34-46

40. McAleese KE, Firbank M, Dey M, Colloby SJ, Walker L, Johnson $\mathrm{M}$ et al (2015) Cortical tau load is associated with white matter hyperintensities. Acta Neuropathol Commun 3:60

41. McAleese KE, Alafuzoff I, Charidimou A, De Reuck J, Grinberg LT, Hainsworth AH et al (2016) Post-mortem assessment in vascular dementia: advances and aspirations. BMC Med 14:129

42. McKeith IG, Dickson DW, Lowe J, Emre M, O’Brien JT, Feldman $\mathrm{H}$ et al (2005) Diagnosis and management of dementia with Lewy bodies: third report of the DLB Consortium. Neurology 65:1863-1872

43. Mirra SS, Heyman A, McKeel D, Sumi SM, Crain BJ, Brownlee LM et al (1991) The Consortium to Establish a Registry for Alzheimer's Disease (CERAD). Part II. Standardization of the neuropathologic assessment of Alzheimer's disease. Neurology 41:479-486

44. Montine TJ, Phelps CH, Beach TG, Bigio EH, Cairns NJ, Dickson DW et al (2012) National Institute on Aging-Alzheimer's Association guidelines for the neuropathologic assessment of Alzheimer's disease: a practical approach. Acta Neuropathol 123:1-11

45. Moran C, Phan TG, Srikanth VK (2012) Cerebral small vessel disease: a review of clinical, radiological, and histopathological phenotypes. Int J Stroke 7:36-46

46. Olichney JM, Ellis RJ, Katzman R, Sabbagh MN, Hansen L (1997) Types of cerebrovascular lesions associated with severe cerebral amyloid angiopathy in Alzheimer's disease. Ann N Y Acad Sci 826:493-497

47. Pantoni L, Garcia JH, Gutierrez JA (1996) Cerebral white matter is highly vulnerable to ischemia. Stroke 27:1641-1646

48. Petzold A (2005) Neurofilament phosphoforms: surrogate markers for axonal injury, degeneration and loss. J Neurol Sci 233:183-198

49. Polvikoski TM, van Straaten EC, Barkhof F, Sulkava R, Aronen HJ, Niinisto L et al (2010) Frontal lobe white matter hyperintensities and neurofibrillary pathology in the oldest old. Neurology 75:2071-2078

50. Schmidt R, Lechner H, Fazekas F, Niederkorn K, Reinhart B, Grieshofer P et al (1994) Assessment of cerebrovascular risk profiles in healthy persons: definition of research goals and the Austrian Stroke Prevention Study (ASPS). Neuroepidemiology 13:308-313

51. Scott JA, Braskie MN, Tosun D, Maillard P, Thompson PM, Weiner $M$ et al (2016) Cerebral amyloid is associated with greater white-matter hyperintensity accrual in cognitively normal older adults. Neurobiol Aging 48:48-52

52. Silbert LC, Dodge HH, Perkins LG, Sherbakov L, Lahna D, Erten-Lyons D et al (2012) Trajectory of white matter hyperintensity burden preceding mild cognitive impairment. Neurology 79:741-747

53. Skrobot OA, Attems J, Esiri M, Hortobagyi T, Ironside JW, Kalaria RN et al (2016) Vascular cognitive impairment neuropathology guidelines (VCING): the contribution of cerebrovascular pathology to cognitive impairment. Brain 139:2957-2969

54. Smallwood A, Oulhaj A, Joachim C, Christie S, Sloan C, Smith $\mathrm{AD}$ et al (2012) Cerebral subcortical small vessel disease and its relation to cognition in elderly subjects: a pathological study in the Oxford Project to Investigate Memory and Ageing (OPTIMA) cohort. Neuropathol Appl Neurobiol 38:337-343 
55. Stokin GB, Lillo C, Falzone TL, Brusch RG, Rockenstein E, Mount SL et al (2005) Axonopathy and transport deficits early in the pathogenesis of Alzheimer's disease. Science 307:1282-1288

56. Tanskanen M, Kalaria RN, Notkola IL, Makela M, Polvikoski T, Myllykangas L et al (2013) Relationships between white matter hyperintensities, cerebral amyloid angiopathy and dementia in a population-based sample of the oldest old. Curr Alzheimer Res 10:1090-1097

57. Thal DR, Rub U, Orantes M, Braak H (2002) Phases of A betadeposition in the human brain and its relevance for the development of AD. Neurology 58:1791-1800

58. Thal DR, von Arnim CA, Griffin WS, Mrak RE, Walker L, Attems J et al (2015) Frontotemporal lobar degeneration FTLDtau: preclinical lesions, vascular, and Alzheimer-related copathologies. J Neural Transm (Vienna) 122:1007-1018

59. Tian J, Shi J, Bailey K, Mann DM (2004) Relationships between arteriosclerosis, cerebral amyloid angiopathy and myelin loss from cerebral cortical white matter in Alzheimer's disease. Neuropathol Appl Neurobiol 30:46-56

60. Tosto G, Zimmerman ME, Hamilton JL, Carmichael OT, Brickman AM, Alzheimer's Disease Neuroimaging I (2015) The effect of white matter hyperintensities on neurodegeneration in mild cognitive impairment. Alzheimers Dement 11:1510-1519

61. Tullberg M, Fletcher E, DeCarli C, Mungas D, Reed BR, Harvey DJ et al (2004) White matter lesions impair frontal lobe function regardless of their location. Neurology 63:246-253

62. van Straaten EC, Harvey D, Scheltens P, Barkhof F, Petersen RC, Thal LJ et al (2008) Periventricular white matter hyperintensities increase the likelihood of progression from amnestic mild cognitive impairment to dementia. J Neurol 255:1302-1308

63. Voelker CC, Garin N, Taylor JS, Gahwiler BH, Hornung JP, Molnar Z (2004) Selective neurofilament (SMI-32, FNP-7 and N200) expression in subpopulations of layer V pyramidal neurons in vivo and in vitro. Cereb Cortex 14:1276-1286

64. Wen W, Sachdev P (2004) The topography of white matter hyperintensities on brain MRI in healthy 60- to 64-year-old individuals. Neuroimage 22:144-154

65. Xie S, Xiao JX, Gong GL, Zang YF, Wang YH, Wu HK et al (2006) Voxel-based detection of white matter abnormalities in mild Alzheimer disease. Neurology 66:1845-1849

66. Yamamoto Y, Ihara M, Tham C, Low RW, Slade JY, Moss T et al (2009) Neuropathological correlates of temporal pole white matter hyperintensities in CADASIL. Stroke 40:2004-2011

67. Yoshita M, Fletcher E, Harvey D, Ortega M, Martinez O, Mungas DM et al (2006) Extent and distribution of white matter hyperintensities in normal aging, MCI, and AD. Neurology 67:2192-2198

68. Zhang Z, Larner SF, Liu MC, Zheng W, Hayes RL, Wang KK (2009) Multiple alphaII-spectrin breakdown products distinguish calpain and caspase dominated necrotic and apoptotic cell death pathways. Apoptosis 14:1289-1298 